УДК 539.42

\title{
Fracture loads prediction on notched short glass fibre reinforced polyamide 6 using the strain energy density
}

\author{
F.T. Ibáñez-Gutiérrez ${ }^{1}$, S. Cicero ${ }^{1}$, V. Madrazo $^{2}$, F. Berto ${ }^{3}$ \\ ${ }^{1}$ LADICIM (Laboratory of Materials Science and Engineering), University of Cantabria, Santander, 39005, Spain \\ ${ }^{2}$ Centro Tecnologico de Componentes, Santander, 39011, Spain \\ ${ }^{3}$ Department of Management and Engineering, University of Padova, Vicenza, 36100, Italy
}

\begin{abstract}
This paper provides an energetic approach useful for the prediction of critical loads on U-notched components without an ideally linear elastic behaviour. The methodology has been applied to 100 fracture specimens of short glass fibre reinforced polyamide 6 (SGFRPA6), combining four different fibre contents $(5,10,30$ and $50 \mathrm{wt} \%)$ and five different notch radii $(0.00,0.25,0.50,1.00$ and $2.00 \mathrm{~mm})$. The proposal combines the application of the strain energy density criterion with the use of the whole absorbed energy in the tensile test (elastic-plastic area under the stress-strain curve). With all of this, the fracture loads have been well estimated in this type of material.

Keywords: short glass fibre reinforced polyamide 6, strain energy density, notch, fracture assessment

DOI 10.24411/1683-805X-2018-11010
\end{abstract}

\section{Расчет разрушающих нагрузок для образцов стеклонаполненного полиамида 6 с надрезом на основе критерия плотности энергии деформации}

\author{
F.T. Ibáñez-Gutiérrez ${ }^{1}$, S. Cicero' ${ }^{1}$, V. Madrazo ${ }^{2}$, F. Berto ${ }^{3}$ \\ ${ }^{1}$ Университет Кантабрия, Сантандер, 39005, Испания \\ ${ }^{2}$ Технологический центр компонентов, Сантандер, 39011, Испания \\ ${ }^{3}$ Падуанский университет, Виченца, 36100, Италия
}

\begin{abstract}
В статье предложен энергетический подход для оценки критических нагрузок на элементы конструкций с U-образным надрезом для неидеального линейно-упругого поведения. Испытания на излом проводили на образцах стеклонаполненного (короткое волокно) полиамида 6 (SGFR-PA6) с разным содержанием волокон $(5,10,30$ и 50 мас. \%) и разным радиусом надреза $(0.00,0.25,0.50,1.00$ и 2.00 мм). Предложенный подход основан на применении критерия плотности энергии деформации с учетом всей поглощенной энергии в ходе испытаний на растяжение (упругопластическая область под кривой растяжения). Проведена оценка разрушающих нарузок для данного типа материала.

Ключевые слова: стеклонаполненный полиамид 6 , плотность энергии деформации, надрез, оценка разрушения
\end{abstract}

\section{Introduction}

The life of structural components is one of the main concerns that design engineers must address. When a stress riser is present (e.g., cracks or notches), it is very important to evaluate the load that leads to failure: the critical load or fracture load.

For many years, different criteria have been developed to assess both the ductile and the brittle behaviour of notched components. One of the first to be proposed, dating back to 1885 , is the strain energy density (SED) criterion [1]. Since then, different SED-based approaches have been formulated (e.g., [2-6]), this being a useful tool in asserting structural safety. Sih introduced the concept of the strain energy density factor $S$ as the product of the strain energy density by a critical distance from the point of singularity [7]. In recent years, the local SED criterion [8-10] has been presented as a combination of Sih's point-wise criterion with Neuber's concept of elementary structural volume [11]. As developed in [8], the local SED criterion is based on the strain energy density averaged over a control volume surrounding the notch tip. In plane problems, the control volume becomes a circle or a circular sector with a radius $R_{\mathrm{c}}$ in the case of cracks or pointed V-notches in mode I or mixed, I + II, mode loading (Fig. 1, $a$ and $b$ ) [9]. 

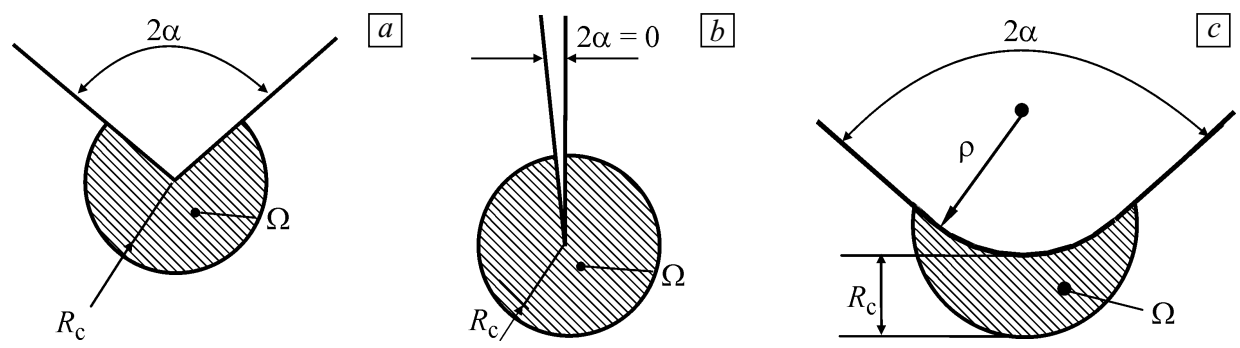

Fig. 1. Control volume (area) for sharp V-notch $(a)$, crack $(b)$ and blunt V-notch $(c)$ under mode I loading

The SED approach is based on the idea that under tensile stress, failure occurs when the mean value of the elastic strain energy referred to an area $W$ is equal to the critical value $W_{\mathrm{c}}$, which varies from material to material [8]. According to Lazzarin-Zambardi [8], if the material is ideally brittle, the value of the critical strain energy density follows:

$$
W_{\mathrm{c}}=\frac{\sigma_{\mathrm{t}}^{2}}{2 E},
$$

where $\sigma_{\mathrm{t}}$ is the ultimate tensile strength and $E$ is the Young's modulus. When the notch opening angle is zero $2 \alpha=0$, the material critical radius $R_{\mathrm{c}}$ can be expressed in terms of the fracture toughness $K_{\mathrm{Ic}}$, the ultimate tensile strength $\sigma_{t}$, and Poisson's ratio $v$ [12]:

$$
\begin{aligned}
& R_{\mathrm{c}}=\frac{(1+v)(5-8 v)}{4 \pi}\left(\frac{K_{\mathrm{Ic}}}{\sigma_{\mathrm{t}}}\right)^{2} \text { for plane strain, } \\
& R_{\mathrm{c}}=\frac{5-3 v}{4 \pi}\left(\frac{K_{\mathrm{Ic}}}{\sigma_{\mathrm{t}}}\right)^{2} \text { for plane stress. }
\end{aligned}
$$

In the case of blunt notches, the total strain energy can be determined over the crescent shape volume (Fig. 1, c) and then the mean value of the SED can be expressed in terms of the elastic maximum notch stress $\sigma_{\max }$ [13]. By applying this condition, the total strain energy can be obtained over the area $\Omega$ (Fig. 1), and the corresponding mean value of the SED follows equation [9]:

$$
\bar{W}=F(2 \alpha) H\left(2 \alpha, \frac{R_{\mathrm{c}}}{\rho}\right) \frac{\sigma_{\max }^{2}}{E},
$$

\begin{tabular}{|c|c|c|c|}
\hline \multicolumn{4}{|c|}{$\begin{array}{c}\text { Values of the function } H \text { when } 2 \alpha=0 \text { for blunted } \\
\text { V-shaped notches (coefficients determined } \\
\text { numerically with } \rho=1 \mathrm{~mm} \text { ) [9] }\end{array}$} \\
\hline$R_{\mathrm{c}} / \rho$ & $v=0.30$ & $v=0.35$ & $v=0.40$ \\
\hline 0.01 & 0.5638 & 0.5432 & 0.5194 \\
\hline 0.05 & 0.5086 & 0.4884 & 0.4652 \\
\hline 0.10 & 0.4518 & 0.4322 & 0.4099 \\
\hline 1.00 & 0.1314 & 0.1217 & 0.1110 \\
\hline
\end{tabular}

where $F(2 \alpha)$ depends on the notch opening angle, $H$ varies

Table 1 with the notch geometry $\left(2 \alpha, R_{\mathrm{c}} / \rho\right)$ and $\sigma_{\max }$ is the maximum elastic stress at the notch tip. Table 1 gathers different values of the $H$ function for U-shaped notches $2 \alpha=0$ [9].

With all of this, the aim of the present research is to estimate the critical load on U-notched short glass fibre reinforced polyamide 6 (SGFR-PA6) by applying the strain energy density criterion. In order to simplify the calculations, the local SED approach explained above is applied. Moreover, as shown below, and due to the non-ideally brittle behaviour of SGFR-PA6, this methodology will be combined with the consideration of the whole (elasticplastic) absorbed energy of the material (i.e., the total area under the stress-strain curve) so as to provide more accurate predictions.

In recent papers $[14,15]$, the analysed experimental programme has been used for both the prediction of the notch effect (by the direct application of the theory of the critical distances [16]) and the validation failure assessment validates a structural integrity assessment methodology (based on the use of failure assessment diagrams and the notch effect corrections provided by the line method, respectively.

\section{Materials and methods}

The experimental programme has been applied to short glass fibre reinforced polyamide 6 (SGFR-PA6) with four
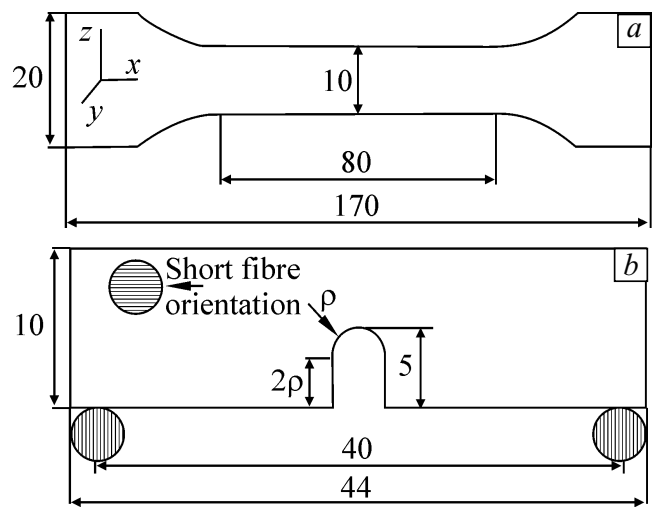

Fig. 2. Tensile $(a)$ and single-edge notch bend test specimens $(b)$. All dimensions are in $\mathrm{mm}$. Thickness is $4 \mathrm{~mm}, \rho$ varying from 0 to $2 \mathrm{~mm}$ 
SGFR-PA6 tensile parameters (average values). $E$-elastic modulus, $\sigma_{0.2}$ - proof stress, $\sigma_{t}$-ultimate tensile strength, $e_{\max }$-strain under maximum load, $v$-Poisson's number ( $x$ refers to the longitudinal direction)

\begin{tabular}{c|c|c|c|c|c|c|c|c}
\hline Fibre content, $\%$ & $E_{x x}, \mathrm{GPa}$ & $E_{y y}=E_{z z}, \mathrm{GPa}$ & $\sigma_{0.2, x}, \mathrm{MPa}$ & $\sigma_{\mathrm{t}, x}, \mathrm{MPa}$ & $e_{\max , x}, \%$ & $v_{x y}=v_{x z}$ & $v_{y x}=v_{z x}$ & $v_{y z}=v_{y z}$ \\
\hline 5 & 3.30 & 3.00 & 66.90 & 72.05 & 2.67 & 0.39 & 0.35 & 0.45 \\
\hline 10 & 3.55 & 3.15 & 70.15 & 78.15 & 2.84 & 0.38 & 0.34 & 0.46 \\
\hline 30 & 6.45 & 4.00 & 105.35 & 128.00 & 3.56 & 0.34 & 0.21 & 0.58 \\
\hline 50 & 12.60 & 5.48 & 161.15 & 192.80 & 2.47 & 0.30 & 0.13 & 0.66 \\
\hline
\end{tabular}

different amounts of fibre content $(5,10,30$ and $50 \mathrm{wt} \%)$. Currently, short fibre reinforced thermoplastics are one of the most widely used technical plastics which are standing in for metal parts in engineering components due to their easy fabrication and good mechanical properties [17]. Adding short glass fibres to PAs leads to a higher heat distortion temperature, strength, abrasion resistance and stiffness, despite the fact that properties can be anisotropic (including mould shrinkage, which implies potential distortion) [18]. Regarding PA6 - unlike many polymers this is accomplished without any loss of impact strength, but strain at maximum load is reduced substantially [19]. The extensive use of these materials makes it essential to study their behaviour when containing stress risers which may appear and endanger the structural integrity of the corresponding component. With this purpose, five different notch radii were covered in the present research: 0 (cracklike defects), 0.25, 0.50, 1.00, and $2.00 \mathrm{~mm}$.

The core of the experimental programme is composed of 108 specimens of SGFR-PA6. They were made by injection moulding with the short glass fibres $(300 \mu \mathrm{m}$ length and $10 \mu \mathrm{m}$ diameter) oriented parallel to the longitudinal axis of the specimens. After injection molding, the mean thickness fibre orientation is $83^{\circ}$ [20] and the effective fibre length is $204.2 \pm 40.9 \mu \mathrm{m}[20,21]$. The geometry and dimensions are shown in Fig. 2, $a$. The specimens were dried in an oven at $100^{\circ} \mathrm{C}$ before testing (tensile or fracture) in order to proceed without moisture. The main mechanical properties were obtained following ASTM D638 [22] as the average values of two tensile tests per fibre content and

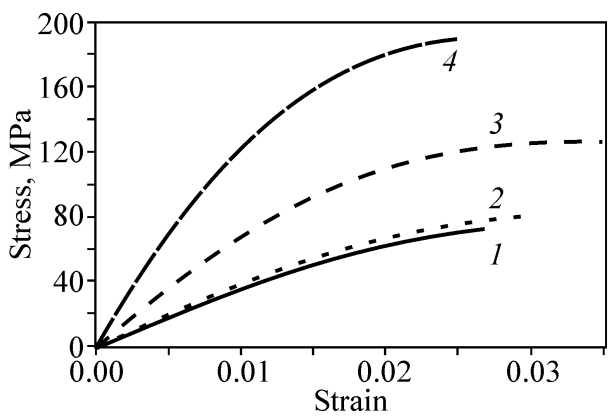

Fig. 3. Strain-stress curves of SGFR-PA6: fibre content 5 (1), 10 (2), 30 (3), $50 \mathrm{wt} \%$ (4) orientation. The results are shown in Table 2. Figure 3 gathers one stress-strain curve per fibre content. It can be observed that the higher the fibre content, the lower the linearity of the curve.

Five single-edge notch bend (SENB) specimens were tested per combination of the 5 notch radii and the 4 fibre contents (i.e., 100 total) following ASTM D5045-99 [23]. These fracture specimens were obtained from the central part of the corresponding tensile samples, the geometry being shown in Fig. 2, b. The notches were obtained by machining perpendicularly to the longitudinal direction of the original specimens. Only one test was invalid (30 wt \%, notch radius $0.5 \mathrm{~mm}$ ). Tables $3-6$ gather the maximum load (fracture load) reached for each fibre content varying the notch radii. Figure 4 shows some examples of the curves obtained, with certain nonlinearity in those with higher fibre content. On the other hand, on five SENB specimens per fibre content, a crack-like defect $(\rho=0 \mathrm{~mm})$ was generated by sawing a razor blade. These specimens were used to derive the corresponding fracture toughness $\left(K_{\text {Ic }}\right.$, see Table 7), which follows equation [23]:

$$
\begin{aligned}
& K_{\mathrm{Ic}}=\left(\frac{P_{\max }}{B W^{1 / 2}}\right) 6\left(\frac{a}{W}\right)^{1 / 2} \times \\
& \times \frac{1.99-a / W(1-a / W)\left(2.15-3.93 a / W+2.7(a / W)^{2}\right.}{(1+2 a / W)(1-a / W)^{3 / 2}} .
\end{aligned}
$$

\section{Estimation of fracture loads}

The assessment of the critical load on short glass fibre reinforced polyamide 6 (SGFR-PA6) is here analysed through the application of the strain energy density criterion [9]. By applying this criterion, it is straightforward to obtain the critical strain energy referred to an area, $W_{\mathrm{c}}$ (Eq. (1)), from the mechanical properties gathered in Table 2.

In order to derive the elastic maximum notch stress from Eq. (4), the different SED criterion parameters should be defined. The $F$ factor value depends on the notch opening angle and, in the case of U-blunt notches with $2 \alpha=0, F$ is equal to 0.785 [9]. In order to obtain the $H$ function, it is necessary to define the material critical radius (Eqs. (2) and (3)). It should be mentioned that when the fracture resistance $K_{\text {mat }}$, associated to particular material and notch radius, is under the limit established by Eq. (6) [24], it may 
Table 3

Description of SGFR-PA6 notched specimens and maximum load obtained (5 wt \%)

\begin{tabular}{c|c|c|c|c|c}
\hline Notch radius $\rho, \mathrm{mm}$ & Specimen & Maximum load $P_{\text {exp }}, \mathrm{N}$ & Notch radius $\rho, \mathrm{mm}$ & Specimen & Maximum load $P_{\text {exp }}, \mathrm{N}$ \\
\hline 0.25 & $5-0.25-1$ & 83.80 & 1.00 & $5-1-1$ & 120.70 \\
\hline 0.25 & $5-0.25-2$ & 82.20 & 1.00 & $5-1-2$ & 99.30 \\
\hline 0.25 & $5-0.25-3$ & 111.00 & 1.00 & $5-1-3$ & 119.10 \\
\hline 0.25 & $5-0.25-4$ & 56.40 & 1.00 & $5-1-4$ & 122.20 \\
\hline 0.25 & $5-0.25-5$ & 77.10 & 1.00 & $5-1-5$ & 106.00 \\
\hline 0.50 & $5-0.5-1$ & 100.10 & 2.00 & $5-2-1$ & 151.60 \\
\hline 0.50 & $5-0.5-2$ & 108.40 & 2.00 & $5-2-2$ & 135.40 \\
\hline 0.50 & $5-0.5-3$ & 96.00 & 2.00 & $5-2-3$ & 126.60 \\
\hline 0.50 & $5-0.5-4$ & 100.60 & 2.00 & $5-2-4$ & 149.70 \\
\hline 0.50 & $5-0.5-5$ & 82.70 & 2.00 & $5-2-5$ & 125.90 \\
\hline
\end{tabular}

Table 4

Description of SGFR-PA6 notched specimens and maximum load obtained (10 wt \%)

\begin{tabular}{c|c|c|c|c|c}
\hline Notch radius $\rho, \mathrm{mm}$ & Specimen & Maximum load $P_{\text {exp }}, \mathrm{N}$ & Notch radius $\rho, \mathrm{mm}$ & Specimen & Maximum load $P_{\text {exp }}, \mathrm{N}$ \\
\hline 0.25 & $10-0.25-1$ & 93.10 & 1.00 & $10-1-1$ & 124.10 \\
\hline 0.25 & $10-0.25-2$ & 105.20 & 1.00 & $10-1-2$ & 116.50 \\
\hline 0.25 & $10-0.25-3$ & 104.50 & 1.00 & $10-1-3$ & 141.00 \\
\hline 0.25 & $10-0.25-4$ & 87.80 & 1.00 & $10-1-4$ & 125.00 \\
\hline 0.25 & $10-0.25-5$ & 78.60 & 1.00 & $10-1-5$ & 119.70 \\
\hline 0.50 & $10-0.5-1$ & 116.20 & 2.00 & $10-2-1$ & 173.80 \\
\hline 0.50 & $10-0.5-2$ & 102.10 & 2.00 & $10-2-2$ & 166.70 \\
\hline 0.50 & $10-0.5-3$ & 93.40 & 2.00 & $10-2-3$ & 167.30 \\
\hline 0.50 & $10-0.5-4$ & 111.10 & 2.00 & $10-2-4$ & 146.40 \\
\hline 0.50 & $10-0.5-5$ & 97.70 & 2.00 & $10-2-5$ & 153.40 \\
\hline
\end{tabular}

Description of SGFR-PA6 notched specimens and maximum load obtained (30 wt \%)

Table 5

\begin{tabular}{c|c|c|c|c|c}
\hline Notch radius $\rho, \mathrm{mm}$ & Specimen & Maximum load $P_{\text {exp }}, \mathrm{N}$ & Notch radius $\rho, \mathrm{mm}$ & Specimen & Maximum load $P_{\text {exp }}, \mathrm{N}$ \\
\hline 0.25 & $30-0.25-1$ & 237.80 & 1.00 & $30-1-1$ & 231.60 \\
\hline 0.25 & $30-0.25-2$ & 220.20 & 1.00 & $30-1-2$ & 251.50 \\
\hline 0.25 & $30-0.25-3$ & 202.50 & 1.00 & $30-1-3$ & 287.90 \\
\hline 0.25 & $30-0.25-4$ & 216.40 & 1.00 & $30-1-4$ & 302.60 \\
\hline 0.25 & $30-0.25-5$ & 205.40 & 1.00 & $30-1-5$ & 246.60 \\
\hline 0.50 & $30-0.5-1$ & 207.10 & 2.00 & $30-2-1$ & 305.80 \\
\hline 0.50 & $30-0.5-2$ & 252.40 & 2.00 & $30-2-2$ & 284.20 \\
\hline 0.50 & $30-0.5-3$ & 251.80 & 2.00 & $30-2-3$ & 269.00 \\
\hline 0.50 & $30-0.5-4$ & - & 2.00 & $30-2-4$ & 263.70 \\
\hline 0.50 & $30-0.5-5$ & 243.30 & 2.00 & $30-2-5$ & 318.30 \\
\hline
\end{tabular}

be considered that plane strain conditions are dominant. In this case, the $R_{\mathrm{c}}$ solution for the tested specimens is given by Eq. (2). The fracture resistance is here understood as the material resistance to fracture for a given notch radius, in stress intensity factor units. On the other hand, when $K_{\text {mat }}$ values are over the limit established by Eq. (7) [24] it may be assumed that plane stress conditions are dominant and the $R_{\mathrm{c}}$ solution follows Eq. (3): 
Description of SGFR-PA6 notched specimens and maximum load obtained (50 wt \%)

\begin{tabular}{c|c|c|c|c|c}
\hline Notch radius $\rho, \mathrm{mm}$ & Specimen & Maximum load $P_{\text {exp }}, \mathrm{N}$ & Notch radius $\rho, \mathrm{mm}$ & Specimen & Maximum load $P_{\text {exp }}, \mathrm{N}$ \\
\hline 0.25 & $50-0.25-1$ & 322.00 & 1.00 & $50-1-1$ & 389.70 \\
\hline 0.25 & $50-0.25-2$ & 338.00 & 1.00 & $50-1-2$ & 394.50 \\
\hline 0.25 & $50-0.25-3$ & 329.40 & 1.00 & $50-1-3$ & 402.40 \\
\hline 0.25 & $50-0.25-4$ & 360.60 & 1.00 & $50-1-4$ & 395.70 \\
\hline 0.25 & $50-0.25-5$ & 335.00 & 1.00 & $50-1-5$ & 389.60 \\
\hline 0.50 & $50-0.5-1$ & 367.40 & 2.00 & $50-2-1$ & 432.30 \\
\hline 0.50 & $50-0.5-2$ & 367.90 & 2.00 & $50-2-2$ & 414.20 \\
\hline 0.50 & $50-0.5-3$ & 364.60 & 2.00 & $50-2-3$ & 426.50 \\
\hline 0.50 & $50-0.5-4$ & 376.90 & 2.00 & $50-2-4$ & 431.00 \\
\hline 0.50 & $50-0.5-5$ & 380.10 & 2.00 & $50-2-5$ & 427.00 \\
\hline
\end{tabular}

plane strain limit

$$
K_{\text {mat }}=\sigma_{\mathrm{y}}\left(\frac{B}{2.5}\right)^{1 / 2},
$$

plane stress onset

$$
K_{\text {mat }}=\sigma_{\mathrm{y}}(\pi B)^{1 / 2}
$$

where $B$ is the thickness of the specimen, and $\sigma_{\mathrm{y}}$ is the yield strength. In practice, the fracture toughness values can be located between the limits established by Eqs. (6) and (7). For this situation, the $R_{\mathrm{c}}$ solution has been obtained here by interpolating equations (2) and (3).
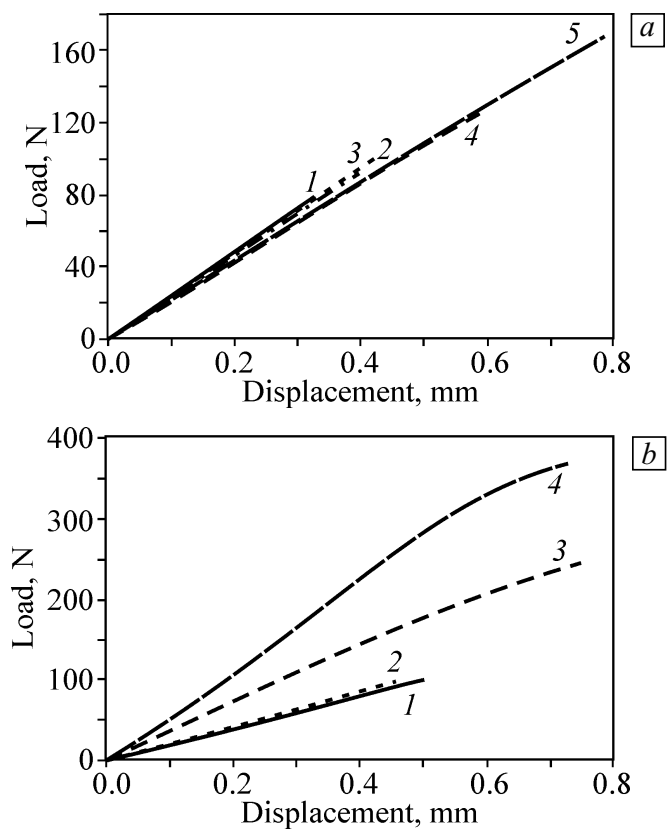

Fig. 4. Load-displacement curve obtained in some SGFR-PA6 specimens for a fibre content of $10 \mathrm{wt} \%, \rho=0.00(1), 0.25$ (2), $0.50(3), 1.00(4), 2.00(5)(a)$; for a notch radius of $0.50 \mathrm{~mm}$, fibre content $5(1), 10(2), 30(3)$, and $50 \mathrm{wt} \%(4)(b)$
Table 1 gathers different $H$ values for some combinations of $\left(R_{\mathrm{c}} / \rho, v\right)$ when $2 \alpha=0$. For each combination of $\left(R_{\mathrm{c}} / \rho, v\right)$ the coefficients $H$ are obtained by interpolation. Once all the parameters are known, the proposal here is to combine the SED criterion for brittle materials with the simplified approach proposed in $[9,10]$. The complete analytical description can be found in [25]. Then, the maximum notch stress $\sigma_{\max }$ is derived from Eqs. (1) and (4) as follows:

$$
\sigma_{\max }=\sqrt{\frac{\sigma_{\mathrm{t}}^{2}}{2 \times 0.785 H\left(2 \alpha=0, R_{\mathrm{c}} / \rho\right)}} .
$$

Table 8 gathers the values obtained for the different parameters and for the different combination of fibre content and notch radius: the critical radius $R_{\mathrm{c}}$, the $H$ factor values, the critical value of the elastic strain energy $W_{\mathrm{c}}$ and the corresponding maximum notch tip stresses $\sigma_{\max }$. Finite elements simulations have been performed with ANSYS to obtain the critical load $P_{\mathrm{SED}}$, which is that one applied on the specimens generating $\sigma_{\max }$ at the corresponding notch tip. The modelling has considered the anisotropy of the material being analysed, with specific properties in width, height and longitudinal directions. Furthermore, the simulation was conducted in purely linear-elastic conditions.

Figure 5, $a$ shows the comparison of the SED prediction $P_{\text {SED }}$ with the experimental results $P_{\text {exp }}$. The experimental data used for each combination of fibre content and notch radius are the average value of those gathered in Tables 3 6. A strong conservatism of the analysis performed can be observed: the relations between the results predicted $P_{\text {SED }}$ and those obtained experimentally $P_{\exp }$ are well below 1 . In addition, the higher the fibre content, the lower the accuracy of the model proposed.

The stress-strain analysis assumes fully linear-elastic behaviour of the material in the tensile curve. However, Figure 3 showed evident nonlinearity for the four different materials (four different fibre contents). Hence, the assump- 
Table 7

Description of SGFR-PA6 cracked specimens and corresponding values of $K_{\text {Ic }}(\rho=0 \mathrm{~mm}$, crack-like defect)

\begin{tabular}{|c|c|c|c|c|c|}
\hline Specimen & $K_{\mathrm{Ic}}, \mathrm{MPam}^{1 / 2}$ & $K_{\mathrm{Ic}, \mathrm{av}}, \mathrm{MPam}^{1 / 2}$ & Specimen & $K_{\mathrm{Ic}}, \mathrm{MPam}^{1 / 2}$ & $K_{\text {Ic,av }}, \mathrm{MPam}^{1 / 2}$ \\
\hline $5-0-1$ & 2.40 & \multirow{5}{*}{1.84} & $30-0-1$ & 5.76 & \multirow{5}{*}{4.77} \\
\hline $5-0-2$ & 1.64 & & $30-0-2$ & 4.74 & \\
\hline $5-0-3$ & 1.78 & & $30-0-3$ & 4.90 & \\
\hline $5-0-4$ & 1.65 & & $30-0-4$ & 4.01 & \\
\hline $5-0-5$ & 1.73 & & $30-0-5$ & 4.44 & \\
\hline $10-0-1$ & 2.46 & \multirow{5}{*}{2.13} & $50-0-1$ & 8.09 & \multirow{5}{*}{8.59} \\
\hline $10-0-2$ & 2.28 & & $50-0-2$ & 8.67 & \\
\hline $10-0-3$ & 1.65 & & $50-0-3$ & 8.56 & \\
\hline $10-0-4$ & 1.81 & & $50-0-4$ & 8.66 & \\
\hline $10-0-5$ & 2.47 & & $50-0-5$ & 8.96 & \\
\hline
\end{tabular}

Table 8

SED parameters for the different approaches proposed and for each combination of fibre content and notch radius

\begin{tabular}{|c|c|c|c|c|c|c|c|c|}
\hline Fibre content, $\%$ & Notch radius $\rho, \mathrm{mm}$ & $R_{\mathrm{c}}, \mathrm{mm}$ & $R_{\mathrm{c}} / \rho$ & $H$ & $W_{\mathrm{c}}, \mathrm{MPa}$ & $\sigma_{\max }, \mathrm{MPa}$ & $W_{\mathrm{c}}^{\prime}, \mathrm{MPa}$ & $\sigma_{\max }^{\prime}, \mathrm{MPa}$ \\
\hline \multirow{4}{*}{5} & 0.25 & 0.136 & 0.542 & 0.190 & \multirow{4}{*}{0.79} & 132.08 & \multirow{4}{*}{1.09} & 155.49 \\
\hline & 0.50 & 0.136 & 0.271 & 0.289 & & 106.89 & & 125.83 \\
\hline & 1.00 & 0.164 & 0.164 & 0.360 & & 95.84 & & 112.82 \\
\hline & 2.00 & 0.271 & 0.135 & 0.384 & & 92.79 & & 109.23 \\
\hline \multirow{4}{*}{10} & 0.25 & 0.160 & 0.640 & 0.170 & \multirow{4}{*}{0.86} & 151.37 & \multirow{4}{*}{1.31} & 186.80 \\
\hline & 0.50 & 0.160 & 0.320 & 0.269 & & 120.28 & & 148.43 \\
\hline & 1.00 & 0.201 & 0.202 & 0.336 & & 107.52 & & 132.69 \\
\hline & 2.00 & 0.387 & 0.194 & 0.342 & & 106.64 & & 131.60 \\
\hline \multirow{4}{*}{30} & 0.25 & 0.400 & 1.599 & 0.124 & \multirow{4}{*}{1.27} & 290.52 & \multirow{4}{*}{3.06} & 450.95 \\
\hline & 0.50 & 0.462 & 0.925 & 0.132 & & 281.69 & & 437.24 \\
\hline & 1.00 & 0.567 & 0.567 & 0.198 & & 229.38 & & 356.04 \\
\hline & 2.00 & 0.702 & 0.351 & 0.269 & & 196.94 & & 305.69 \\
\hline \multirow{4}{*}{50} & 0.25 & 0.571 & 2.286 & 0.131 & \multirow{4}{*}{1.48} & 424.48 & \multirow{4}{*}{3.13} & 618.34 \\
\hline & 0.50 & 0.630 & 1.260 & 0.131 & & 424.48 & & 618.34 \\
\hline & 1.00 & 0.685 & 0.685 & 0.180 & & 362.42 & & 527.93 \\
\hline & 2.00 & 0.785 & 0.393 & 0.264 & & 299.30 & & 435.99 \\
\hline
\end{tabular}

tion of the linear approach (SED criterion) is not adequate for this type of material.

Thus, another methodology is here proposed to increase the accuracy of the fracture load prediction. The analysis performed will consider the whole area under the stressstrain (i.e., the total absorbed energy $W_{\mathrm{c}}^{\prime}$ ). Once the area is obtained, the corrected maximum notch stress $\sigma_{\max }^{\prime}$ follows:

$$
\sigma_{\max }^{\prime}=\sqrt{\frac{E W_{\mathrm{c}}^{\prime}}{0.785 H\left(2 \alpha=0, R_{\mathrm{c}} / \rho\right)}} .
$$

The estimation of the new fracture loads $P_{\text {SED }}^{\prime}$ was finally obtained by repeating the finite element analysis (i.e., obtaining the load that generates the corresponding $\sigma_{\max }^{\prime}$ at the notch tip). Table 8 shows the different values of $W_{\mathrm{c}}^{\prime}$ and $\sigma_{\max }^{\prime}$ obtained, while Fig. 5, $b$ compares the predictions of the fracture load $P_{\text {SED }}^{\prime}$ with the experimental results $P_{\text {exp }}^{\prime}$. As shown in Fig. 3, the loss of linearity in the behaviour of tensile specimens is higher when the fibre content increases. Hence, the difference between $W_{\mathrm{c}}$ and $W_{\mathrm{c}}^{\prime}$ and therefore, between $\sigma_{\max }$ and $\sigma_{\max }^{\prime}$, increases with the fibre content 

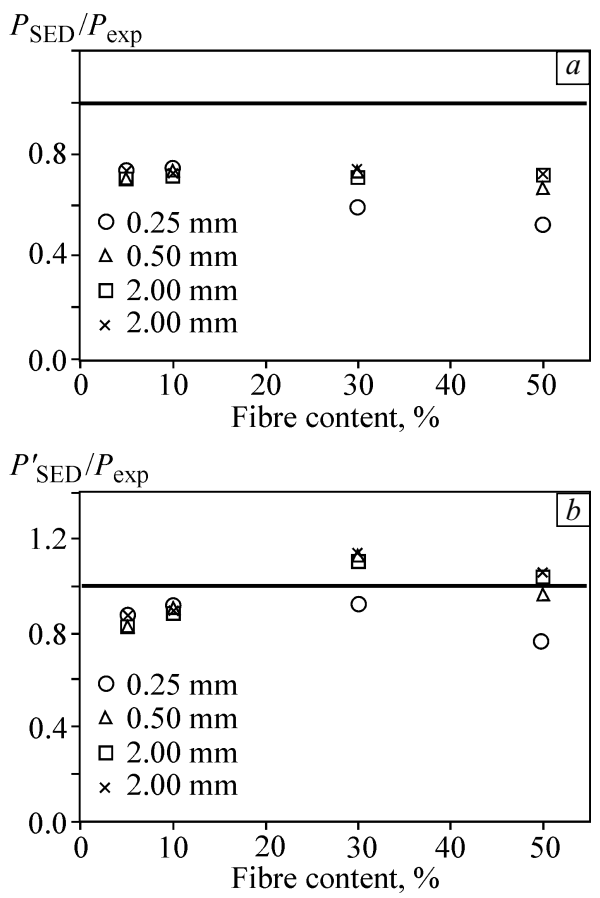

Fig. 5. Comparison of the critical load values obtained with $W_{\mathrm{c}}(a)$ and $W_{\mathrm{c}}^{\prime}(b)$ experimental data

(given that the situation deviates from linear-elastic conditions). By applying this second approach, a clear reduction in the conservatism of the results can be observed. The prediction is accurate not only for high fibre contents but also for low fibre contents. Comparing the fracture loads predicted with the experimental results obtained, the relation is close to 1 . Thus, the range of accuracy is much higher here than that observed when notches are treated as cracks and comparable to that obtained through other approaches such as the theory of critical distances [e.g., 14, 26, 27] or the combination of the TCD and failure assessment distances $[15,28,29]$. Summing up, the application of this approach to this type of material is, therefore, both simple and safe.

\section{Conclusions}

This paper provides and validates a methodology for the assessment of fracture loads in notched specimens of short glass fibre reinforced polyamide 6 (SGFR-PA6) using the strain energy density criterion. The core of the experimental programme is composed of 100 fracture (SENB) specimens combining different notch radii (from 0 up to $2 \mathrm{~mm}$ ) and different fibre contents (from 5 up to $50 \mathrm{wt} \%$ ).

The initial assessment, which assumes linear-elastic behaviour, predicts fracture loads that are far from the results obtained experimentally. Given that SGFR-PA6 develops an elastic-plastic behaviour, another methodology has been proposed considering the whole absorbed energy in the tensile test (elastic-plastic area under the stress-strain curve). With this new approach, the estimation of the critical load is closer to the results obtained within the experimental programme. The prediction of fracture loads on SGFR-PA6 using the methodology proposed gives accurate results, closer to the physics of the problem. Therefore, the local approach is again shown as a powerful tool in fracture assessment.

\section{Acknowledgments}

The authors of this work wish to extend their gratitude to the Spanish Ministry of Science and Innovation for the financial support of the Project MAT2014-58443-P, on the results of which this paper is based.

\section{References}

1. Beltrami E. Sulle Condizioni di Resistenza dei Corpi Elastici. - Il Nouvo Cimento 18, 1885.

2. Sih G.C. A Special Theory in Crack Propagation: Methods of Analysis and Solutions of Crack Problems, Mechanics of Fracture. - Leyden: Noordhoof, Int. Publ., 1973. - P. 21-45.

3. Kipp M.E., Sih G.C. The strain energy density failure criterion applied to notched elastic solids // Int. J. Solid. Struct. - 1975. - V. 11. P. 153-173.

4. Gillemot L.F., Czoboly E., Havas I. Fracture mechanics applications of absorbed specific fracture energy: notch and unnotched specimens // Theor. Appl. Fract. Mech. - 1985. - V. 4. - P. 39-45.

5. Glinka $G$. Energy density approach to calculation of inelastic strainstress near notches and cracks // Eng. Fract. Mech. - 1985. - V. 22. P. 485-508.

6. Ellyn F. Fatigue Damage, Crack Growth and Life Prediction. - London: Chapman \& Hall, 1967.

7. Sih G.C. Strain-energy-density factor applied to mixed mode crack problems // Int. J. Fract. - 1974. - V. 10. - P. 305-321.

8. Lazzarin P., Zambardi R. A finite-volume-energy based approach to predict the static and fatigue behavior of components with sharp V-shaped notches // Int. J. Fract. - 2001. - V. 112. - P. 275-298.

9. Berto F., Lazzarin P. Recent developments in brittle and quasi-brittle failure assessment of engineering materials by means of local approaches // Mater. Sci. Eng. R. Rep. - 2014. - V. 75. - P. 1-48.

10. Berto F., Lazzarin P. A review of the volume-based strain energy density approach applied to V-noches and welded structures // Theor. App. Fract. Mech. - 2009. - V. 52. - P. 183-194.

11. Neuber H. Theory of Notch Stresses. - Berlin: Springer-Verlag, 1958.

12. Yosibash Z., Bussiba Ar., Gilad I. Failure criteria for brittle elastic materials // Int. J. Fract. 2004. - V. 125. - P. 307-333.

13. Seweryn A. Brittle fracture criterion for structures with sharp notches // Eng. Fract. Mech. - 1994. - V. 47. - P. 673-681.

14. Ibáñez-Gutiérrez F.T., Cicero S., Carrascal I.A., Procopio I. Effect of fibre content and notch radius in the fracture behavior of short glass fibre reinforced polyamide 6: An approach from the theory of critical distances // Compos. B. Eng. - 2016. - V. 94. - P. 299-311.

15. Ibáñez-Gutiérrez F.T., Cicero S. Fracture assessment of notched short glass fibre reinforced polyamide 6: An approach from failure assessment diagrams and the theory of critical distances // Compos. B. Eng. - 2017. - V. 111. - P. 124-133.

16. Taylor D. The Theory of Critical Distances: A New Perspective in Fracture Mechanics. - London: Elsevier, 2007.

17. Mallick P.K. Fiber Reinforced Composites, Materials Manufacturing and Design. - CRC Press, 2007.

18. Brydson J.A. Plastics Materials. - Guildford: Butterworth Heinemann, 1989.

19. Crawford R.J. Plastics Engineering. - Oxford, 1983. 
20. Diego Cavia S. Estudio de Viabilidad de Reutilización de Poliamida Reforzada con Fibra de Vidrio Corta Para Inyectar Placas de Sujeción de Vía de Ferrocarril de Para Alta Velocidad (AVE). - PhD Dissertation. - Santander: University of Cantabria, 2014.

21. Casado J.A., Carrascal I., Diego S., Polanco J.A., Gutiérrez-Solana F., Garcia A. Mechanical behaviour of recycled reinforced polyamide railway fasteners // Pol. Comp. - 2009. - V. 31. - P. 1142-1149.

22. ASTM D638-10 Standard Test Method for Tensile Properties of Plastics // Annual Book of ASTM Standards. - V. 08.03. - Philadelphia: Am. Soc. Testing and Materials, 2004.

23. ASTM D5045-99 (2007) e1. Standard Test Methods for Plane-Strain Fracture Toughness and Strain Energy Release Rate of Plastic Materials // Annual Book of ASTM Standards. - V. 08.03. - Philadelphia: American Society for Testing and Materials, 2004.

24. Knott J.F. Fundamentals of Fracture Mechanics. - ButterworthsLondon, 1973.

25. Lazzarin P., Berto F. Some expressions for the strain energy in a finite volume surrounding the root of blunt V-notches // Int. J. Fract. 2005. - V. 135. - P. 161-185.
26. Cicero S., Madrazo V., Carrascal I.A. Analysis of notch effect in PMMA by using the theory of critical distances // Eng. Fract. Mech. 2012. - V. 86. - P. 56-72.

27. Cicero S., García T., Castro J., Madrazo V., Andres D. Analysis of notch effect on the fracture behaviour of granite and limestone: an approach from the theory of critical distances // Eng. Geol. - 2014. V. 177. - P. 1-9.

28. Cicero S., Madrazo V., Garcia T. On the assessment of U-shaped notches using failure assesment diagrams and the line method: Experimental overview and validation // Theor. Appl. Fract. Mech. 2015. - V. 80. - P. 235-241.

29. Cicero S., Garcia T., Madrazo V. Structural integrity analysis of notched ferritic steels operating within their ductile-to-brittle transition zone: An approach from failure assessment diagrams and the notch master curve // Eng. Fail. Anal. - 2015. - V. 58. - P. 134-148.

Поступила в редакцию 21.04.2017 г

Сведения об авторах

Francisco Tomas Ibáñez-Gutiérrez, PhD, Researcher, University of Cantabria, Spain, ibanezft@unican.es

Sergio Cicero, PhD, Prof., University of Cantabria, Spain, ciceros@unican.es

Virginia Madrazo, PhD, Researcher, Centro Tecnologico de Componentes, Spain, vmadrazo@ctcomponentes.com

Filippo Berto, PhD, Prof., University of Padova, Italy, berto@gest.unipd.it, filippo.berto@unipd.it 